\title{
Mídia e Desenvolvimento Sustentável \\ Uma Análise da Cobertura Jornalística das Conferências Ambientais da ONU
}

http://dx.doi.org/10.21527/2237-6453.2020.53.32-45

Recebido em: $3 / 5 / 2018$

Aceito em: 30/7/2020

Clóvis Reis, ${ }^{1}$ Michel Imme Sabbagh, ${ }^{2}$ Yanet Maria Reimondo Barrios ${ }^{3}$

\begin{abstract}
RESUMO
O presente artigo analisa as implicações da cobertura da mídia em relação ao conceito de desenvolvimento sustentável. A investigação centrou-se em apresentar um estudo de caso sobre a cobertura das Conferências Ambientais da Organização das Nações Unidas (ONU) em 1972, 1992, 2002 e 2012 pelo Jornal de Santa Catarina (JSC). Dessa forma, e por meio de uma análise morfológica e de conteúdo, o trabalho explora o tratamento do conceito de desenvolvimento sustentável pela mídia e como se poderia avançar no entendimento das suas dimensões e na necessidade do debate permanente sobre tais questões. O estudo mostrou que o JSC divulgou de maneira superficial o conceito de desenvolvimento sustentável, concentrando-se, especialmente, em informações oficiais e na reprodução de notícias de agências nacionais e internacionais.
\end{abstract}

Palavras-chave: Mídia. Desenvolvimento sustentável. Jornal de Santa Catarina.

MEDIA AND SUSTAINABLE DEVELOPMENT:

\section{AN ANALYSIS OF THE JOURNALISTIC COVERAGE OF THE UN ENVIRONMENTAL CONFERENCES}

\section{ABSTRACT}

This article analyzes the implications of media coverage in relation to the concept of sustainable development. The investigation focused on presenting a case study on the coverage of the Environmental Conferences of the United Nations (UN) in 1972, 1992, 2002 and 2012 by Jornal de Santa Catarina (JSC). In this way, and through a morphological and content analysis, the work explores the treatment of the concept of sustainable development by the media, and how it could advance in understanding its dimensions and the need for permanent debate on such issues. The study pointed out that JSC superficially disseminated the concept of sustainable development, focusing especially on official information and the reproduction of news from national and international agencies.

Keywords: Media. Sustainable development. Santa Catarina Journal.

\footnotetext{
${ }^{1}$ Doutor em Comunicação pela Universidade de Navarra, Espanha. Professor do Programa de Pós-Graduação em Desenvolvimento Regional da Universidade Regional de Blumenau (Furb). http://lattes.cnpq.br/6005495485532707. https://orcid.org/0000-0002-8131-9229. professorclovisreis@gmail.com

${ }^{2}$ Mestre em Desenvolvimento Regional pela Universidade Regional de Blumenau (Furb). Assessor de imprensa da Universidade Regional de Blumenau (Furb). http://lattes.cnpq.br/7901894574987770. https://orcid.org/0000-0002-3200-1345. jornalista40@yahoo.com.br

${ }^{3}$ Mestre e doutoranda em Desenvolvimento Regional pela Universidade Regional de Blumenau (Furb). Bolsista da Coordenação de Aperfeiçoamento de Pessoal de Nível Superior, Capes, Brasil. http://lattes.cnpq.br/4192388082131279. https://orcid.org/0000-0002-2461-6841. yanet.barrios89@gmail.com
} 
Há pouco mais de meio século, a preocupação com o esgotamento dos recursos do planeta e a busca de alternativas para que os mesmos não sejam devastados por uma escala de produção avassaladora, tornaram-se pauta nos debates políticos e científicos mundiais (PEREIRA, 2015). Ao analisar o padrão atual de desenvolvimento, Sachs (2002) identifica sinais incontestáveis de insustentabilidade, expressa na degradação ambiental e nas desigualdades sociais. Além disso, alerta que as transformações necessárias supõem a existência de um movimento multissetorial e global, capaz de mudar os principais eixos civilizatórios da sociedade contemporânea.

Os debates acerca do atual modelo, socialmente injusto e ambientalmente devastador (GUIMARÃES, 2001), emergem da valorização da consciência ecológica com o propósito de garantir a sobrevivência das gerações futuras (JACOBI, 2005). Nesse sentido, Sachs (1993) define o desenvolvimento sustentável, também chamado de ecodesenvolvimento, como um estilo de desenvolvimento orientado pela busca de autonomia e pela satisfação prioritária das necessidades básicas das populações envolvidas. Ele considera vital planejar, eficientemente, o padrão de desenvolvimento e formula cinco dimensões da sustentabilidade: a ecológica, a social, a econômica, a espacial e a cultural. Este olhar transdisciplinar propõe que o atual modelo de desenvolvimento deve ser substituído gradualmente por outro, que contemple estas cinco questões - ou oito -, com a inclusão das dimensões ambiental, política nacional e política internacional (SACHS, 2002) -, o que implicaria profundas mudanças em todos os setores e níveis sociais.

Hanai (2012) entende a sustentabilidade como um conjunto de princípios funcionais dos sistemas, que permite definir um estilo de desenvolvimento que inclui objetivos múltiplos, segundo determinadas escalas de valores e contextos variáveis que vão se transformando no tempo e retroalimentam-se permanentemente.

Segundo Born (2000 apud SOUSA; FERNANDES, 2002), para haver maior pressão social e política em torno do tema será necessário garantir ao público, por meio da mídia, o acesso à informação. Isso permitirá construir novas formas de compreensão de como obter crescimento, garantindo os recursos e considerando aspectos sociais em suas práticas. Para Novaes (2005), só a comunicação pode retirar as questões ambientais do "gueto em que estão colocadas" e levar a sociedade a entender o impacto das suas ações. Esse ponto de vista resgata uma discussão antiga sobre o papel da comunicação de massa: informar, educar, entreter, persuadir, promover a integração individual e coletiva, na realização do bem-estar social (BELTRÃO, 1992).

Para Habermas (1992), a esfera pública constitui-se em uma estrutura comunicacional do agir orientado pelo entendimento. Nesse sentido, é fundamental que as questões relacionadas ao desenvolvimento sustentável integrem tanto as discussões da esfera pública quanto a pauta midiática. Trigueiro (2005) alerta que o trabalho do jornalista não deve se limitar a denunciar o que está errado, pois deve sinalizar também o rumo e a perspectiva para a sociedade por meio das histórias que conta. De acordo com Oliveira (2007), a função pedagógica da mídia, particularmente em relação ao desenvolvimento sustentável, tem algumas implicações. As grandes redes de comunicação estão organizadas como indústrias e, como tal, buscam sobrevivência mercadológica dentro do sistema capitalista. "Ainda que falem de meio ambiente e de sustentabilidade, não perdem de vista o modelo que as sustenta" (SOUZA; FERNANDES, 2002, p. 4). 
Para Boff (1999), o que presenciamos é uma cobertura viciada numa ética que não é a do cuidado nem a da responsabilidade. Bueno (2012) indica que a cobertura da mídia relacionada às questões de sustentabilidade e do meio ambiente não mantêm uma frequência compatível com a sua importância, e parece não ter competência do rol que desempenha ou disposição para exercê-lo. Ainda nesta mesma linha de considerações, acrescenta que devemos sacudi-la, reformulá-la e criar alternativas cidadãs em nome do país e do planeta que desejamos para as novas gerações. Nesse sentido, precisa-se de uma mídia com perspectiva crítica e consciente do seu papel de educador e formador de opiniões.

Nas últimas décadas, os estudos que relacionam a mídia e o desenvolvimento sustentável ganharam destaque na pesquisa acadêmica, adotando diferentes perspectivas de investigação (BOYAGODA, 2017; BOYKOFF; ROBERTS, 2007; CHAND, 2017 ; FISCHER; HAUCKE; SUNDERMANN, 2017; JANOUŠKOVÁ et al., 2019; YOUNG; McCOMAS, 2016). Tais debates concentram-se, fundamentalmente, em aspectos relacionados à produção de notícias, o discurso público e a cobertura jornalística, baseados em estudos de caso, de revisão da literatura e estudos de caso comparativo. Outras pesquisas apontam a responsabilidade da mídia em destacar a causa real por trás das questões ambientais (PARVEEN, 2016). De maneira geral, percebe-se a falta de uma abordagem metodológica comum para analisar a cobertura midiática dos múltiplos aspectos relacionados ao desenvolvimento sustentável.

Levando em conta os elementos anteriormente expostos, o presente trabalho tem como propósito explorar as implicações da cobertura da mídia em relação ao conceito de desenvolvimento sustentável. A pesquisa analisa a cobertura das Conferências Ambientais da ONU em 1972, 1992, 2002 e 2012 pelo Jornal de Santa Catarina (JSC), e busca o cumprimento dos seguintes objetivos: 1) classificar as notícias sobre os quatro eventos ambientais da ONU em Gêneros Jornalísticos; 2) analisar a cobertura do JSC em relação às dimensões da sustentabilidade apontadas por Sachs (2002); e 3) propor um modelo metodológico no qual as implicações da cobertura da mídia em relação ao conceito de desenvolvimento sustentável possam ser capturadas e analisadas. A partir dos resultados, são tiradas conclusões e fornecidas pistas sobre as oportunidades e direções para as próximas décadas de pesquisa neste campo particular de estudos.

\section{MÍDIA E DESENVOLVIMENTO SUSTENTÁVEL}

Segundo Barkemeyer e Holt (2012), nas últimas décadas houve uma mudança na maneira como o público percebe as questões ambientais e os conceitos associados ao desenvolvimento sustentável. $O$ debate político-intelectual em torno de eventos, como Conferência de Estocolmo (1972), Relatório Brundtland (1987), Conferência Eco/Rio (1992), Protocolo de Kyoto (1997), Conferência de Johannesburgo (2002) e a discussão acadêmica de autores como Sachs (1993, 2002, 2007), Lélé (1991), Boff (1999), Leff (2002), entre outros, consolidam tal afirmação. Para Szerszyski et al. (2000), a mídia desempenha um papel fundamental no desenvolvimento do discurso público sobre estes temas. Ela molda a cidadania e pode promover a formação de um senso de conexão global. Este aspecto é também comentado por Givel (2006), que destaca o papel da mídia na promoção de mudanças de comportamento e na orientação da atenção do público para uma preocupação específica. 
Sobre o assunto, Mazur e Lee (1993) afirmam que o efeito mais amplamente aceito dos meios de comunicação sobre a opinião pública é a definição da agenda, ou seja, a colocação de certas questões ou problemas na pauta pública. A teoria da definição da agenda afirma que a mídia realmente não influencia o que pensamos, mas, antes, coloca nossa mente no que pensar (BARAN, 2009). Dessa forma, a mídia desempenha um papel importante na formação da realidade, determinando a relevância de certas questões. Para Aruguete (2017), nas últimas décadas o ecossistema midiático sofreu uma virada de 180 graus. O surgimento de novas plataformas ocorreu paralelamente às dificuldades econômicas e financeiras enfrentadas pela mídia tradicional, cuja capacidade monolítica de demarcar a percepção pública generalizada tem sido ameaçada, em razão, em parte, do surgimento de um número crescente de fontes alternativas que permitem aos cidadãos coletar e compartilhar informações sem ter de recorrer a jornalistas ou outros profissionais que, geralmente, estabelecem as rotas da informação (ARUGUETE, 2017).

McCombs (2005, p. 545) ressalta que a heterogeneidade midiática, disponível na Internet, podia levar a diversas agendas entre o público, uma situação que significaria "o fim da definição de agenda como a conhecemos". Nesse sentido, um público que não compartilha uma agenda comum pode achar impossível envolver-se em ação coletiva porque seus membros discordam do que é importante para a sociedade (FEEZELL, 2017). Os jornais, no entanto, ainda são um dos meios mais importantes para a transformação da informação e a determinação da opinião pública (PARVEEN, 2016).

Mídia e desenvolvimento sustentável parecem encontrar-se num momento crítico da história: o da crise dos modelos de desenvolvimento com altos valores de produção e consumo, o da exploração sem limites dos recursos naturais e o do fenômeno das redes sociais (PARVEEN, 2016). É nesse contexto que se impõe como missão da mídia a promoção do conceito de desenvolvimento sustentável.

Em que pese toda a divulgação das quatro principais conferências ambientais da Organização das Nações Unidas (ONU) em 1972, 1992, 2002 e 2012, instituições internacionais apontam a existência de um vazio informativo sobre o conceito sistêmico de desenvolvimento sustentável. Segundo a organização Liderança para o Meio Ambiente e Desenvolvimento (LEAD, 2001), os preparativos para a cúpula de Johannesburgo/2002 e os assuntos relacionados ao desenvolvimento sustentável não foram objeto de atenção da mídia nem do debate interno nos Estados Unidos. Superficialidade e desequilíbrio no enquadramento das principais dimensões da sustentabilidade têm caracterizado, de maneira geral, a cobertura da imprensa em torno do tema (FISCHER; HAUCKE; SUNDERMANN, 2017).

Sobre a falta de cobertura dos meios de comunicação social nas questões de sustentabilidade, a Rede Cidadã ${ }^{4}$ indica que este fenômeno tem como base a ênfase excessiva dos interesses políticos na economia, a influência do setor industrial, o apoio da publicidade em massa e o marketing do consumismo. Tais elementos contribuem para a falta de sensibilização do público sobre o desenvolvimento sustentável e para a pouca

\footnotetext{
${ }^{4}$ A Rede Cidadã para o Desenvolvimento Sustentável - ou CitNet (Citizen Network) - é uma rede sem fins lucrativos que reúne organizações, comunidades e indivíduos que trabalham no desenvolvimento sustentável nos Estados Unidos (LEAD, 2001).
} 
consciência pública. Para Oliveira (2007), a atuação da mídia não vem acompanhando as reais necessidades da sociedade e do meio ambiente, nem tem preocupação interdisciplinar. Além disso, afirma que o seu interesse pelos assuntos ambientais é invariavelmente determinado por desastres ou circunstâncias trágicas, o que, de certa forma, é correto. Falta-Ihe, ainda, porém, perceber a urgência de abrir espaço para novas pautas que tratem a problemática socioambiental de maneira interdisciplinar (OLIVEIRA, 2007).

Esse panorama tem mudado nos últimos anos, levando em conta que o público começou a usar as mídias sociais como fonte de notícias. Tais canais permitiram que ativistas e grupos ambientais menos estabelecidos publiquem suas próprias informações, ignorando o papel de guardião dos jornalistas no qual eles selecionam e estruturam histórias de perspectivas mais restritas (CARPENTER et al., 2016). Dessa forma, blogs, sites e contas em Twitter ou Facebook constituem espaços de ativismo, disseminação de informações e discussão sobre questões ambientais.

A dependência pública dos meios de comunicação social para obter informações sobre questões relacionadas com o desenvolvimento sustentável, entretanto, originou a necessidade de um princípio de responsabilidade da mídia na educação ambiental. Para Nerone (2002), quando se trata destes temas a mídia parece estar quase isenta de responsabilidade. Em razão de seus interesses comerciais, os meios de comunicação são, muitas vezes, percebidos como canais um tanto controversos para comunicar a sustentabilidade. Sharma (2000) afirma que, embora a cobertura da poluição industrial e da biodiversidade ameaçada tenha atingido o pico antes da Cúpula da Terra de 1992, os relatórios foram rapidamente eliminados porque os conglomerados de mídia perceberam que essas tendências poderiam afetar os lucros e causar uma depressão nos investimentos corporativos.

É preciso destacar que a mídia desempenha um papel fundamental na promoção de informações, dados e análises que ajudam os cidadãos a tomar decisões e escolhas em sua vida diária. Isso inclui informações que têm "a capacidade de informar, criar debate e engajamento em torno de questões-chave de sustentabilidade, como assuntos ambientais urgentes, direitos humanos e justiça econômica e social" (ASEF, 2013, p. 9). O que a sociedade necessita da mídia é a produção de mensagens que abordem a versão integradora e completa da problemática ambiental, refletindo interesses coletivos, desenvolvendo um discurso que avance a mera constatação e atravessando as fronteiras estruturais, em que interesses políticos e econômicos se organizam (OLIVEIRA, 2007).

Como o desenvolvimento sustentável exige uma mudança complexa e de longo prazo, Oepen e Hamacher (2000) consideram a falta de entendimento da sociedade, quanto à razão de ser dessa mudança, sinal de um problema fundamental na comunicação. Nesse sentido, Barry (2003) assevera que o foco na comunicação sobre sustentabilidade é essencial para fazer a alteração necessária de um discurso de elites a um discurso mais aberto e acessível à comunidade. Assim, na emergente sociedade da informação, precisa-se de uma mídia que consiga evoluir de um mero meio de divulgação e disseminação de informações e notícias para um espaço público, aberto e democrático que possibilite o intercâmbio de informações e opiniões. Nesse contexto, é necessá- 
rio um repensar substantivo das práticas jornalísticas e do próprio papel da mídia nos processos de formação de opinião e de deliberação política (FREY, 2002; FEEZELL, 2017; ORIOLA; OGBEMI, 2016).

\section{METODOLOGIA}

Percebendo que a mídia pode influenciar a percepção e o entendimento do público sobre questões relacionadas com o desenvolvimento sustentável, buscou-se uma compreensão da sua abordagem na cobertura das Conferências Ambientais da Organização das Nações Unidas (ONU) em 1972, 1992, 2002 e 2012 pelo Jornal da Santa Catarina (JSC). Assim, este artigo apresenta, a partir de agora, amparado no método da análise morfológica e de conteúdo, os procedimentos utilizados para a coleta de dados. Eles são: a classificação dos conteúdos em Gêneros Jornalísticos para entender de que forma são publicados pelo JSC e, posteriormente, a análise da relação do conceito de desenvolvimento sustentável divulgado pela imprensa, em particular pelo JSC, objeto do estudo de caso.

Para a análise morfológica e de conteúdo, adotou-se a metodologia proposta por Marques de Melo (1972) e critérios utilizados por Bardin (2010). A análise morfológica "pode ser definida através da comparação entre os elementos utilizados na sua composição gráfica, ou seja, títulos, ilustrações e textos" (MARQUES DE MELO, 1972, p. 100). Segundo Bardin (2010), com a análise de conteúdo o pesquisador busca compreender o sentido da comunicação tentando encontrar outra significação implícita. Nesse sentido, esta técnica "é uma correspondência entre as estruturas semânticas ou lingüísticas e as estruturas psicológicas ou sociológicas (por exemplo: condutas, ideologias e atitudes) dos enunciados" (BARDIN, 2010, p. 41).

Bardin (2010) identifica nesta técnica três fases fundamentais. A primeira, classificada como pré-análise, estabelece o esquema de trabalho, procedimentos e indicadores que orientarão a interpretação do material. A segunda fase está dedicada à leitura, codificação, classificação e categorização do material selecionado, buscando fazer o desmembramento dos textos em unidades para descobrir os diferentes núcleos de sentido. "Classificar elementos em categorias impõe a investigação do que cada um deles têm em comum com outros. O que vai permitir seu agrupamento é a parte comum existente entre eles" (BARDIN, 2010, p. 118). A última fase tem como objetivo interpretar os resultados e torná-los válidos por meio de técnicas quantitativas e/ou qualitativas em busca de padrões, tendências ou relações implícitas.

O critério de seleção das notícias sobre o evento partiu da coleta e leitura de todos os jornais, página por página, durante o período de realização das conferências, num espaço anterior e posterior que, no total, deveria somar 30 dias de análise para extrair textos publicados sobre cada um dos quatro eventos ambientais da ONU (1972, 1992, 2002 e 2012). Todas as notícias foram lidas, fotografadas, digitadas e digitalizadas para separar os textos vinculados às conferências.

A pesquisa fez um recorte histórico de 40 anos (1972-2012) na composição da amostra. As primeiras coleções verificadas foram as de maio e junho de 1972, por conta da primeira Conferência Mundial da ONU sobre Homem e o Meio Ambiente, em Estocolmo, na Suécia, entre os dias 5 e 16 de junho. Foram coletadas 11 matérias em 1972. O mesmo procedimento de coleta e classificação ocorreu com as coleções de 1992, de 
onde foi possível coletar 35 textos sobre a Conferência das Nações Unidas sobre o Meio Ambiente e o Desenvolvimento, mais conhecida como ECO-92, no Rio de Janeiro, ocorrida entre os dias 3 e 14 de junho. Da mesma forma que a pesquisa anterior, foram definidos dez dias antes e dez dias depois do evento como período de validação dos textos para pesquisa, somando 30 dias.

Na terceira cúpula, em 2002, o levantamento recolheu 12 matérias sobre a Conferência das Nações Unidas sobre Ambiente e Desenvolvimento Sustentável em Johanesburgo, na África do Sul, realizada entre 26 de agosto e 4 de setembro. Na quarta cúpula, a investigação coletou 25 textos da Conferência das Nações Unidas sobre Desenvolvimento Sustentável, a chamada Rio+20, que ocorreu entre 13 e 22 de junho, novamente no Rio de Janeiro. Todos os 83 textos foram fotografados e digitados, com exceção das 25 matérias de 2012, fornecidas no modelo digital pela redação do Jornal de Santa Catarina.

Os 83 textos coletados foram classificados em categorias extraídas dos Gêneros Jornalísticos que interessavam à investigação: data da matéria; títulos das matérias; editoria (seção) em que foram publicadas e o número da página; se houve citação de fontes oficiais e/ou extraoficiais; o tamanho de cada texto; se era fruto de produção da redação local do JSC, sucursais do veículo ou contratado de agências de notícias externas (nacionais e internacionais); se havia foto, ilustração ou charge; se era texto noticioso, uma coluna assinada ou mesmo uma opinião do jornal (os editoriais); se a matéria era resultado de alguma repercussão local vinculada à conferência; e, por fim, se o texto foi contemplado com chamada de capa.

Depois das categorizações dos Gêneros Jornalísticos, passou-se para a etapa da análise da relação do conceito de desenvolvimento sustentável divulgado pelo JSC. Com a ajuda do software QSR NVivo, foram analisadas as palavras mais frequentes em cada conferência e que tivessem ligação direta com o marco teórico da pesquisa. Esse sistema oferece vários recursos de pesquisa para reunir, organizar e contar textos e palavras com o fim de proceder à análise de conteúdo. O sistema tem a vantagem de permitir justificar as descobertas com rigor científico, armazenando ou exportando dados e imagens do objeto pesquisado para salvar em arquivos do computador (SABBAGH, 2014).

Cada uma das dimensões da sustentabilidade propostas por Sachs (2002) foi relacionada com as palavras-chave selecionadas. A ideia foi entender como a imprensa (JSC) pautou a cobertura sobre tais conferências e sobre o conceito de desenvolvimento sustentável. Nesse sentido, as palavras-chave e as nuvens de palavras ajudaram a construir pistas sobre a forma com que foram editadas as publicações jornalísticas em determinados momentos da história, nos quais o jornal teve participação como difusor dos fatos e dos discursos de cada época, em 1972, 1992, 2002 e 2012, seja com sua própria produção ou de agências de notícias contratadas. Realizada a codificação, passou-se à contabilização e apresentação dos resultados.

\section{CASO DO ESTUDO: O JORNAL DE SANTA CATARINA}

O Jornal de Santa Catarina (JSC) tem sede em Blumenau/SC e iniciou suas publicações em 21 setembro de 1971, quando o então governador Colombo Salles acionou a impressora off set, a primeira de Santa Catarina. Manteve, assim, a tradição e o pioneirismo do município no âmbito da indústria da comunicação. Além do primeiro jornal off 
set, Blumenau teve ainda a primeira emissora de televisão do Estado - a TV Coligadas - filiada da Rede Globo, e a primeira emissora rádio do Estado - a Rádio Clube (prefixo PRC 4). O novo diário em rede estadual, que competia com veículos de Florianópolis e Joinville, teve a semente plantada no Departamento de Jornalismo da TV Coligadas, dirigido por Nestor Fedrizzi, professor da Faculdade de Meios de Comunicação da PUC de Porto Alegre (PEREIRA, 1992).

O JSC abrange 54 municípios da mesorregião do Vale do Itajaí - que corresponde a um terço da economia e potencial de consumo do Estado. Incorporado ao Grupo RBS em 1992, o jornal é marcado pelo pioneirismo, investimentos em novas tecnologias, apreço pelo interesse público e o compromisso com a comunidade. Credibilidade, independência e excelência editorial fazem do jornal o líder local (SABBAGH, 2014).

\section{COBERTURA E GÊNEROS JORNALÍSTICOS}

O jornal publicou, entre notícias, colunas assinadas e editoriais sobre as conferências ambientais da ONU, apenas 11 textos em 1972; 35 em 1992; 12 em 2002 e 25 textos em 2012. A mais completa cobertura foi a de 1992, que triplicou em relação a 1972 e ainda superou a de 2012. Vinte anos após a Eco/92, apesar de todas as mudanças e desastres ambientais ocorridos no planeta, não se percebeu uma evolução na cobertura da cúpula. Tais dados revelam a falta de uma pauta regular e de repercussão regional/ local sobre o assunto, e até descompromisso editorial em ampliar o debate público de temas de grande interesse. Trata-se de eventos que discutiram questões ambientais e modelos de desenvolvimento sustentável para mudar os rumos de um impasse civilizatório que vem esgotando, em velocidade assustadora e em uma escala sem precedentes, os recursos naturais do planeta, com impactos negativos sobre a qualidade de vida da população (TRIGUEIRO, 2005). Não obstante, tal cobertura não ampliou o espaço nas páginas do jornal.

Chama atenção o fato de apenas na Eco/92 o JSC ter publicado chamadas na capa. A primeira página é a vitrine do jornal, para a qual são selecionados títulos, textos e fotos que destaquem a força de atração do conteúdo interno de jornal, ou seja, se não está destacado ou mesmo citado na capa, há que se concluir que o JSC não considerou importante as Conferências Ambientais da ONU em 1972, 2002 e 2012. Na média, $75 \%$ das matérias foram escritas com base em fontes oficiais do evento, revelando uma cobertura protocolar e até descompromissada com a agenda ambiental plural. A cobertura poderia ser ampliada com entrevistas e apresentações de fontes extraoficiais e da própria comunidade, das universidades, dos pesquisadores, dos representantes de entidades sociais, e de organizações não governamentais.

Para divulgar as quatro conferências da ONU, o JSC utilizou dois terços de matérias contratadas junto a agências externas (66,3\%). Apenas um terço eram textos próprios de sua redação (33,7\%). Em correspondência com o resultado anterior, dois terços das matérias publicadas são notícias (55 de 83 textos da amostra); 25,3\% são colunas assinadas ( 21 de 83 textos) e 8,43\% revelaram a opinião do jornal (sete de 83 textos). Levando-se em conta as quatro conferências, verifica-se que $66,3 \%$ das publicações tiveram caráter informativo e $33,7 \%$ constituíam-se de textos opinativos. Um terço dos 83 textos recebeu imagem do evento ou de produção local/arquivo. Por fim, e não menos importante, um dado revela a baixa repercussão local/regional em termos de co- 
bertura dos temas discutidos nas conferências. Apenas 18 dos 83 textos $(15,4 \%)$ fizeram referência a questões locais na cobertura dos eventos, enquanto a expressiva maioria $(84,6 \%)$ não relaciona a discussão das conferências ambientais a aspectos da realidade na qual o jornal está inserido.

Os fenômenos das enchentes, enxurradas e deslizamento de morros em Blumenau e no Vale do Itajaí nos anos 1983, 1984, 1990, 2008 e 2011, por exemplo, não receberam pautas conectadas com as Cúpulas Ambientais da ONU. A decisão pode passar para a opinião pública a impressão de que tais fenômenos, suas consequências e prejuízos para a população, inclusive com perdas de vidas, não estão altamente imbricados com o atual modelo de desenvolvimento e as mudanças climáticas. Este dado revela o escasso aproveitamento da oportunidade de enriquecer a cobertura dos eventos ouvindo os pesquisadores, ambientalistas, ONGs, universidades, gestores públicos, associações de classe, empresários e trabalhadores da região na qual o jornal atua. Ao invés disso, o periódico optou pela reprodução preponderante de notícias nacionais e internacionais $(66,3 \%)$ sobre as conferências ambientais da ONU.

\section{COBERTURA E DIMENSÕES DA SUSTENTABILIDADE}

Para o segundo momento da análise da cobertura das Conferências Ambientais da ONU, a pesquisa selecionou 25 palavras-chave para cada uma das seis dimensões da Sustentabilidade de Sachs, produzindo, a partir daí, uma média aritmética para cada uma das dimensões. Nesse sentido, destacam-se como palavras mais frequentes na amostra geral: ambiental (com 69 textos e 206 citações, ocupando 83\% dos 83 textos da amostra); meio-ambiente (com 57 textos e 120 citações, ocupando 60\%); desenvolvimento (com 52 textos e 132 citações, ocupando 62\%) e desenvolvimento sustentável (com 34 textos e 60 citações, que participou em $40 \%$ dos textos da amostra de 83 textos). "Preservação", "energia" e "biodiversidade" ganham força dentro da análise.

Selecionadas as palavras-chave (150 no total), foi possível medir o peso e a distribuição do conteúdo jornalístico sobre cada dimensão da sustentabilidade individualmente. Em primeiro lugar, apareceu a dimensão ecológica/ambiental, com 736 referências e 29,4 de média. Depois veio a dimensão econômica, com 9,2 de média ponderada, seguida das dimensões política (média de 8,52$)$; social $(4,7)$; espacial $(2,92)$ e, em último lugar, a cultural, com a pior média ponderada de citações no jornal $(0,32)$. Estes dados coincidem com as reflexões apresentadas precedentemente no marco teórico deste trabalho e refletem a postura da imprensa, de um modo geral, em sua divulgação jornalística sobre as Conferências Ambientais da ONU: destaque para as dimensões ecológica, econômica e política, em detrimento às dimensões cultural, espacial e social.

Enfatizado isso, pode-se continuar com a análise crítica do resultado de cada dimensão da sustentabilidade. É importante ressaltar que, independentemente do resultado, é possível perceber quais são as palavras frequentes, as pouco citadas e as não citadas. Este último grupo integra o discurso do "não dito" pela imprensa, que também pode ser levado em conta para esta e futuras pesquisas.

Começando pela dimensão econômica, com 230 referências, "indústrias/empresas/fábricas" foi uma palavra composta que recebeu impressionantes 45 citações nos textos, seguida de "economia" (29), "desenvolvimento econômico" (23), "econômica" (15) e "economia verde" (11). Nove das palavras-chave quase não tiveram menção na 
cobertura das conferências. Pode-se inferir que a imprensa ignora ou bloqueia as discussões relacionadas com "sustentabilidade econômica", "modernização industrial", "tecnologias sustentáveis", "marketing verde", "obsolescência programada", "reciclagem", "padrão de consumo" e "tecnologias limpas" (SABBAGH, 2014).

$\mathrm{Na}$ dimensão ecológica/ambiental, com 736 referências, as palavras mais citadas foram "meio ambiente/ambiental" (326), "preservação/preservar/proteção" (64), "água em geral" (56), "planeta" (55), "natureza" (35), "biodiversidade" (30), "poluição/ poluentes" (28) e "ecológica/ecologia" (25). Além disso, os resultados mostraram que a pauta do JSC foi escassa ou protocolar na divulgação de temas como "sustentabilidade ecológica", "bem-estar ambiental”, "degradação", "ecossistemas", "impactos ambientais", "regeneração", "aquecimento global”, "ar", "espécies ameaçadas" e "mudanças climáticas", palavras-chave que quase não foram citadas.

Terceira melhor colocada no ranking de dimensões mais citadas pela imprensa, a dimensão política teve 213 referências nas suas palavras-chave afins e uma média 8,52. Aquelas com mais ocorrências foram: "desenvolvimento sustentável" (62), "países ricos" (42), "países pobres" (31), "sustentabilidade" (20), "fórum global" (15) e "responsabilidade comum global". Aqui, a palavra "desenvolvimento sustentável" merece ser bem explicada na sua pontuação: 24 citações referem-se ao nome das cúpulas de 2002 e 2012. São meras citações institucionais, o que reduziria o resultado da palavra-chave para 38 ocorrências. As palavras "igualdade" e "política social" não foram citadas nenhuma vez nos 83 textos.

Na dimensão social, com 118 referências, foi possível observar que o JSC e a imprensa em geral não discutem temas relacionados com "sustentabilidade social", "abismo social", "cidadania", "dignidade social", "qualificação", "acesso à internet" e "informática", sete palavras-chave que não foram mencionadas nenhuma vez. Entre as restantes 18 palavras-chave, foram citadas com maior frequência "qualidade de vida" (12), "educação" (16), "pobreza" (21 citações) e "fome" (23). A julgar pelos resultados, a imprensa ainda explora pouco ou nada algumas questões cruciais para um desenvolvimento sustentável mais igualitário e justo (SABBAGH, 2014).

Com relação à dimensão espacial, com 73 referências, o JSC ignorou praticamente todas as palavras-chave. As mais citadas foram: "região/regionais" (21), "população" (17), "território" (8), "habitantes" (7), "crescimento demográfico/populacional" (6), "incentivo/desenvolvimento regional" (4), "áreas urbanas" (3) e "planejamento/espaço urbano" (2). A dimensão cultural aparece com somente oito (8) referências. Das 25 palavras-chave afins, 19 não receberam nenhuma citação do JSC durante a cobertura das quatro Conferências da ONU. A mais citada foi "cultura", com três ocorrências. As restantes cinco palavras receberam apenas uma citação: "experiência local", "diversidade cultural", "cultura nativa", "integração racial" e "agricultura familiar".

É possível concluir a análise destacando alguns pontos sobre a pontuação das seis dimensões da sustentabilidade. Das 44 palavras-chave que não foram citadas pelo JSC, 38 delas (86,3\%) pertencem às dimensões cultural (19), espacial (12) e social (7). As dimensões mais prestigiadas pelo JSC foram a ecológica/ambiental (com apenas duas citações zero), a econômica (com uma palavra-chave não citada nos textos) e a política (com apenas três palavras sem retorno). 


\section{A NECESSIDADE DE MAIS QUESTIONAMENTO}

O debate sobre o trabalho da imprensa revela características da cobertura jornalística na sua relação com o debate sobre o desenvolvimento sustentável e as dimensões da sustentabilidade. A dimensão cultural propõe a busca das raízes endógenas dos modelos de modernização, e o equilíbrio entre respeito à tradição e inovação, com capacidade de autonomia para um projeto nacional integrado (SACHS, 2002). A dimensão espacial busca promover uma configuração rural-urbana mais equilibrada e uma melhor distribuição territorial dos assentamentos humanos e atividades econômicas. Lamentavelmente, porém, estas questões foram ignoradas pelo jornal durante as conferências ambientais analisadas. A sustentabilidade social mereceria estar no topo das preocupações e da agenda da imprensa, pois, segundo Sachs (1993), está relacionada com a criação de um processo de desenvolvimento civilizatório baseado nos sujeitos, uma maior equidade na distribuição de renda, nos direitos e nas condições da população, e em reduzir a distância entre os padrões de vida dos mais ricos e mais pobres.

A sustentabilidade implica, porém, objetivos de longo prazo e fatores multidimensionais, que devem ser evidentes na cobertura noticiosa. Os resultados da pesquisa vêm ao encontro do indicado por Keating (1994), ao salientar que a maioria das notícias sobre desenvolvimento sustentável concentra-se na perspectiva ambiental, mas raramente analisa seu enfoque social. Sobre o assunto, Bueno (2011) argumenta que o entendimento que os jornalistas e os veículos têm do conceito de desenvolvimento sustentável é contaminado pela visão financista. Segundo o autor, esta perspectiva, restrita e pautada por fontes comprometidas com determinados e poderosos interesses, acaba privilegiando a vertente econômica em detrimento da social, cultural ou política.

Outro aspecto a se destacar é a tendência da mídia a se concentrar apenas nos acontecimentos atuais, contingentes e sensacionalistas (desastres, catástrofes, crises e tragédias) e não prestar muita atenção aos potenciais impactos do comportamento humano presente no futuro (HOUSTON; PFEFFERBAUM; ROSENHOLTZ, 2012). Para Alexander (2002), embora a maioria dos jornais e revistas cubra os problemas ambientais, as histórias que examinam a interação e o efeito cumulativo desses problemas não estão sendo trazidas à atenção pública consistentemente.

Kensicki (2004) sugere que o conteúdo da mídia pode estar incentivando a apatia em relação a questões ambientais como um problema social e reduzindo o senso de responsabilidade pessoal e coletiva. Raramente a mídia esclarece as causas da poluição, das mudanças climáticas, seus efeitos, os agentes responsáveis, e nem sugere ações corretivas. É responsabilidade da mídia fornecer informação que consiga aumentar a conscientização, mudanças de valores e promover ações, proporcionando uma forma de educação ambiental (SUSMAYADI et al., 2014).

Ficou claro na pesquisa que a imprensa ainda não está preparada para esse desafio. No caso das Conferências Ambientais, a cobertura informou muitas vezes negativamente, mas não ajudou a formar nova consciência. Os avanços são lentos, na medida em que a própria ONU reconhece que apenas quatro dos 90 objetivos ambientais mais importantes acertados nos últimos 40 anos tiveram avanços significativos (SABBAGH, 2014). Uma nova postura dos veículos de comunicação exigirá uma visão mais crítica e questionadora do atual modelo de desenvolvimento. 


\section{CONSIDERAÇÕES FINAIS}

O foco central deste artigo buscou refletir sobre as implicações da cobertura da mídia em relação ao conceito de desenvolvimento sustentável. Nesse sentido, apresentou-se um estudo de caso sobre a cobertura das Conferências Ambientais da Organização das Nações Unidas (ONU) em 1972, 1992, 2002 e 2012 pelo Jornal da Santa Catarina. Com isso, procurou-se refletir como a mídia evoluiu no tratamento do conceito de desenvolvimento sustentável e como poderia avançar no entendimento das dimensões da sustentabilidade e na necessidade do debate permanente sobre tais questões.

Para o estudo de caso, foi realizada uma análise morfológica e de conteúdo com o fim de classificar as notícias sobre os quatro eventos ambientais da ONU $(1972,1992$, 2002 e 2012) em Gêneros Jornalísticos e analisar a relação do conceito de desenvolvimento sustentável divulgado pelo JSC. Assim, a pesquisa fez um recorte histórico de 40 anos (1972-2012) na composição da amostra. Em termos gerais, evidenciou-se um vazio informativo na cobertura noticiosa destes eventos. O estudo mostrou que o Jornal de Santa Catarina tratou de maneira superficial e protocolar o conceito de desenvolvimento sustentável, concentrando-se, especialmente, em informações oficiais e na reprodução de notícias de agências nacionais e internacionais.

A falta de profundidade, escopo, interação com atores locais e pautas conectadas com a realidade local, sinalizaram a necessidade do aprofundamento dos conhecimentos e o debate público sobre o tema. Isto constitui, sem dúvidas, um obstáculo para a consolidação do conceito de desenvolvimento sustentável na região. O JSC é só um exemplo. De forma geral, os modelos de negócios em mídia buscam conteúdo popular e, lamentavelmente, as histórias de sustentabilidade não são (WEINGART et al., 2000). Muitas vezes, os impactos ambientais e sociais só são relatados após a ocorrência de um desastre, ao invés de aumentar a resiliência nas comunidades por meio de matérias jornalísticas proativas sobre questões de vulnerabilidade social e ambiental.

Deve-se distinguir, como limitação desta pesquisa, que, dada a necessidade de circunscrever o período do estudo, a pesquisa trabalhou com eventos específicos. Para se obter uma visão mais ampla, poderiam ser estudadas todas as edições de um ano ou fazer comparação com outros jornais. A partir dos resultados deste estudo, sugere-se que pesquisas futuras examinem questões relacionadas com as implicações sociais da cobertura noticiosa sobre temas relacionados com as dimensões da sustentabilidade. Além disso, seria interessante sugerir a cobertura sobre o tema nas mídias sociais, cuja presença e importância na formação da opinião pública vêm crescendo com a popularização das novas tecnologias da comunicação.

\section{REFERÊNCIAS}

ALEXANDER, C. Missing the "Big Story" in Environment Coverage. Nieman Reports, v. 56, n. 4, p. 45-47, 2002.

ASEF. Asia-Europe Foundation. Sustainable Development reporting for Journalists. Asef Media Handbook. $9^{\text {th }}$ ed. Índia: Asef Journalists' Colloquium, 2013.

ARUGUETE, N. The agenda setting hypothesis in the new media environment. Comunicación y Sociedad, n. 28, p. 35-58, 2017.

BARAN, S. J. Introduction to mass communication: media literacy and culture. $5^{\text {th }}$ ed. New York: McGraw-Hill, 2009.

BARDIN, L. Análise de conteúdo. 2. ed. Lisboa: Edições 70, 2010. 
BARKEMEYER, Ralf; HOLT, Diane. Media coverage of sustainable development issues - attention cycles or punctuated equilibrium. Sustainable Development, v. 20, n. 1, p. 1-17, 2012.

BARRY, J. Communicating a Politics of Sustainable Development. In: Encyclopedia of Life Support Systems (EOLSS). Oxford, UK: Unesco, 2003 Disponível em: www.eolss.net. Acesso em: fev. 2017.

BELTRÃO, Luiz. Iniciação à filosofia do jornalismo. 2. ed. São Paulo: USP, 1992. (Clássicos do jornalismo brasileiro).

BOFF, L. Saber cuidar: ética do humano - compaixão pela Terra. Petrópolis: Vozes, 1999.

BOYAGODA, E. W. Reporting green: an exploratory study of news coverage of environmental issues in Sri Lankan newspapers. Asia Pacific Journal of Advanced Business and Social Studies, v. 3, n. 1, p. 307-317, 2017.

BOYKOFF, M.; ROBERTS, J. T. Media coverage of climate change: current trends, strengths, weaknesses. Human Development Report 2007/2008. 2007. Disponível em: https://rockyanderson.org/wp-content/ uploads/2016/04/MediacoverageofCC-current-trends.pdf.

BUENO, Wilson. Jornalismo ambiental e transparência corporativa: o marketing verde como estratégia de mistificação. Ação Midiática, Estudos em Comunicação, Sociedade e Cultura, v.1, n. 2, 2011. Disponível em: http://revistas.ufpr.br/acaomidiatica/article/view/26426. Acesso em: fev. 2017.

BUENO, Wilson. A imprensa pós-Rio + 20. Entrevista ao portal revistapontocom. 2012. Disponível em: http://www.revistapontocom.org.br/entrevistas/a-imprensa-posrio20. Acesso em: fev. 2017.

CARPENTER, S. et al. The Roles of Social Media in Promoting Sustainability in Higher Education. International Journal of Communication, n. 10, p. 4.863-4.881, 2016.

CHAND, S. Newspaper coverage of climate change in Fiji. A content analysis. Pacific Journalism Review, v. 23, n. 1, p. 169-185, 2017.

COHEN, B. C. The Press and Foreign Policy. Princeton: Princeton University Press, 1963.

FEEZELL, J. T. Agenda Setting through Social Media: The Importance of Incidental News Exposure and Social Filtering in the Digital Era. Political Research Quarterly, p. 1-13, 2017. DOI: 10.1177/1065912917744895.

FISCHER, D.; HAUCKE, F.; SUNDERMANN, A. What does the media mean by "sustainability" or "sustainable development?" An empirical analysis of sustainability terminology in German newspapers over two decades. Sustainable Development, v. 25, n. 6, p. 610-624, 2017.

FREY, Klaus. O papel da imprensa na política ambiental. Revista de Ciências Humanas, Florianópolis: EDUFSC, out. 2002. Disponível em: https://periodicos.ufsc.br/index.php/revistacfh/article/view/25266. Acesso em: fev. 2017.

GIVEL, M. Punctuated equilibrium in limbo: The tobacco lobby and US state policymaking from 1990 to 2003. Policy Studies Journal, v. 34, n. 3, p. 405-418, 2006.

GIDDENS, Anthony. Modernidade e identidade. Rio de Janeiro: Jorge Zahar Editor, 2002.

GUIMARÃES, R. A ética da sustentabilidade e a formulação de políticas de desenvolvimento. In: VIANA, G. et al. (org.). O desafio da sustentabilidade. São Paulo: Fundação Perseu Abramo, 2001.

HABERMAS, Jürgen. Further Reflections on the Public Sphere. In: CALHOUN, Craig (ed.). Habermas and the Public Sphere. Cambridge, MA: MIT Press, 1992.

HANAI, F. Y. Desenvolvimento sustentável e sustentabilidade do turismo: conceitos, reflexões e perspectivas. Revista Brasileira de Gestão e Desenvolvimento Regional, v. 8, n. 1, p. 198-231, 2012.

HOUSTON, J. B.; PFEFFERBAUM, B.; ROSENHOLTZ, C. E. Disaster News: framing and frame changing in coverage of Major U.S. natural disasters, 2000-2010. Journalism and Mass Communication Quaterly, v. 89, n. 4, p. 606-623, 2012.

JACOBI, P. R. Educação ambiental: o desafio da construção de um pensamento crítico, complexo e reflexivo. Educação e Pesquisa, v. 31, n. 2, p. 233-250, 2005.

JANOUŠKOVÁ, S. et al. Sustainable Development. a poorly communicated concept by mass media. Another challenge for SDGs? Sustainability, v. 11, n. 11, 2019.

KEATING, M. Media, fish and sustainability: a paper on sustainable development and the Canadian news media. Ottawa: National Round Table on the Environment and the Economy, 1994.

KENSICKI, L. J. No Cure for What Ails Us: The Media-Constructed Disconnect Between Societal Problems and Possible Solutions. Journalism and Mass Communication Quarterly, v. 81, n. 1, p. 53-73, 2004.

LEAD. Leadership for Environment and Development. Roads to the Summit. London: Panos, 2001.

LEFF, Enrique. Epistemologia ambiental, 3 ed. São Paulo: Cortez, 2002.

LÉLÉ, S. M. Sustainable Development: a critical review. World Development, v. 19, n. 6, p. 607-621, 1991.

MARQUES DE MELO, José. Estudos de jornalismo comparado. São Paulo: Pioneira Editora. 1972. 
MAZUR, A.; LEE, J. Sounding the global alarm: Environmental issues in the US national news. Social Studies of Science, v. 23, n. 4, p. 681-720, 1993.

MCCOMBS, M. E. A Look at Agenda-Setting: Past, Present and Future. Journalism Studies, v. 6, n. 4, p. 543557,2005

NERONE, J. C. Social Responsibility Theory. In: MCQUAIL, D. (ed.). McQuail's. Reader in Mass Communication Theory. London: Sage Publications, 2002. p. 185-193.

NOVAES, Washington. In: TRIGUEIRO, A. (org.). Mundo sustentável. Abrindo espaço na mídia para um planeta em transformação (prefácio). Rio de Janeiro: Globo, 2005.

OEPEN, M.; HAMACHER, W. Communicating the Environment: Environmental Communication for Sustainable Development. Frankfurt, Germany: Peter Lang GmbH, 2000.

OLIVEIRA, Polline Almeida de. Uma análise da cobertura socioambiental. 2007. Disponível em: http:// www.observatoriodaimprensa.com.br/news/view/uma_analise_da_cobertura_socioambiental. Acesso em: fev. 2017.

ONU Brasil. Roteiro para a localização dos objetivos de desenvolvimento sustentável. 2016. Disponível: https://nacoesunidas.org/wp-content/uploads/2017/06/Roteiro-para-a-Localizacao-dos-ODS.pdf.

ONU Brasil. Indústria, inovação e infraestrutura. 2017. Disponível em: https://nacoesunidas.org/wp-content/uploads/2017/06/Documento-Tem\%C3\%A1tico-ODS-9-Industria-Inova\%C3\%A7\%C3\%A3o-e-Infra_ 11junho2017.pdf.

ORIOLA, M. O.; OGBEMI, O. B. News Analysis as a Media Content for Public Opinion Formation and Moulding. Benin Mediacom Journal, n. 10, p. 77-90, 2016.

PARVEEN, H. A study of the coverage of environment and sustainable development in Indian English dailies. Journal of Innovations, v. XI, n. 2, p. 80-86, 2016.

PEREIRA, Joana Castro. Questões ambientais e relações internacionais, uma nova (des)ordem global - o papel das Relações Internacionais na promoção de um sistema internacional concertado. Rev. Bras. Polít. Int. [on-line], v. 58, n. 1, p. 191-209, 2015.

PEREIRA, Moacir. Imprensa e poder: a comunicação em Santa Catarina. Florianópolis: Editora Lunardelli, 1992.

SABBAGH, Michel. Comunicação e desenvolvimento sustentável: uma análise da cobertura do Jornal de Santa Catarina sobre as Conferências Ambientais da ONU de 1972, 1992, 2002 e 2012. 2014. Dissertação (Mestrado) - Universidade Regional de Blumenau, Furb, PPGDR, 2014.

SACHS, I. Estratégias de transição para o século XXI. Desenvolvimento e meio ambiente. São Paulo: Studio Nobel; Fundap, 1993.

SACHS, I. Caminhos para o desenvolvimento sustentável. Rio de Janeiro: Garamond, 2002.

SACHS, I. Rumo à ecossocioeconomia. Teoria e prática do desenvolvimento. Organização Paulo Freire Vieira. São Paulo: Cortez, 2007.

SHARMA, D. Genetic Modification, Food and Sustainable Development: Telling the Story. In: Smith, J. (ed.). The Daily Globe: Environmental Change, the Public and the Media. London: Earthscan Publications, 2000. p. 79-94.

SHAW, E. Agenda-Setting and Mass Comunication Theory. International Journal for Mass Communication Studies, v. 25, n. 2, p. 96-105, 1979.

SOUZA, C.; FERNANDES, F. Mídia e meio ambiente: limites e possibilidades. Universidade de Taubaté. Departamento de Comunicação Social, 2002. Disponível: http://site.unitau.br//scripts/prppg/humanas/ download/midiaemeioambienteN2-2002.pdf. Acesso em: fev. 2017.

SUSMAYADI, I. M. et al. Sustainable disaster risk reduction through effective risk communication media in Parangtritis tourism area, Yogyakarta. Procedia Environmental Sciences, v. 20, p. 684-692, 2014.

SZERSZYSKI, B. et al. Mediating global citizenship. In: SMITH, J. (ed.). The daily globe environmental change, the public and the media. London: Earthscan, 2000. p. 97-114.

TRIGUEIRO, André. Mundo sustentável: abrindo espaço da mídia para um planeta em transformação. São Paulo: Globo, 2005.

YOUNG, C.; MCCOMAS, K. Media's Role in Enhancing Sustainable Development in Zambia. Journal Mass Communication and Society, v. 19, n. 5, p. 626-649, 2016.

WEINGART, P. et al. Risks of Communication: Discourses on Climate Change in Science, Politics, and the Mass Media. Public Understanding of Science, v. 9, p. 261-283, 2000. 